Journal Plus Education, ISSN: 1842-077X, E-ISSN (online) 2068-1151 Vol XIX (2018), No. 1. pp. 325-328

\title{
PHILOSOPHICAL REFLECTIONS UPON A FEW THEORIES AND PRACTICES IN THE EDUCATIONAL SYSTEM
}

\author{
Matei SIMANDAN, Ph.D., \\ "Aurel Vlaicu" University of Arad \\ msimandan@yahoo.co.uk
}

\section{- Review -}

\section{Constantin Cucos, Education. Refoundations, Dynamics, Prefigurations, Iasi, Polirom Publishing House, 2017, 278p, ISBN 978-973-46-6760-4}

For several years now, professor Constantin Cucos has published papers which approach a wide array of issues pertaining to pedagogy and psycho-pedagogy, the methodology of cultural and intercultural education, educational management, the technologization of education, aesthetic and religious education or the theory and methodology of education.

Polirom Publishing House has recently published one of his books of philosophical reflections upon the terms and practices of the educational system, with reference to the means of connecting the Romanian educational system to the European and the international ones. Far from being a mere analysis of the field mentioned above, the author proposes a journey along the numerous restructuring and innovations within the educational system and examines critically the set of hindrances and challenges typical to a society based on knowledge, without omitting the formulation of certain opinions and perspectives regarding the areas where one needs to continue intervening.

From the very first chapter, Cucos develops the idea that the innovative process in education is continuous, and "the reformation of education does not solely rely on the normative framework expressed through curricular documents, procedures, methodologies and recommendations; it regards mentalities and attitudes, the actions which are less visible and which can be tested directly" (p.19). Of all the aspects approached by the author, I will focus on the following aspects: education does not only regard the present, but the perspective of a person and a community; education must begin with a general training which can then be oriented towards an authentic professionalization; any educational enterprise involves focusing on certain educational contents, as well as on the means of reaching them; apart from transmitting knowledge and values, education involves the interrogation and the applicability of what is accumulated. 
The author insists upon the idea that the purpose of intellectual education is that each of its beneficiaries can become autonomous, namely to judge "with their own head the science or knowledge of others, to look for explanations, to refuse prejudices, to be inventive, critical and objective with one's own views" (p.28).

Extensive space is devoted to the processes of change and innovations, the dynamics of education being considered a reality which ought to be assumed by all the factors involved in society. Based on this idea, I would like to focus on the problem of investing in the student, on the need to elaborate training programs which are connected to his real needs of individual and social development, to institute certain scientific criteria of evaluating the outcomes of education, the increase of responsibility in the decision-making process by involving specialists, the implementation of public policies regarding budget allocation and staff training, the promotion of educational policies meant to connect the Romanian educational system with the tendencies taking place at a European and international level.

Having arrived in this point of our discussion, professor Cucos resorts to a philosophical argumentation by which he succeeds to identify the major interrogations of the "refoundation - dynamics - prefiguration" ternary, as well as the relationship created between education and the other human practices. The major guidelines resulting from the author's approach are structured around ontological issues (natural elements of education), praxeological issues (elements of educational procedure and practices), epistemological issues (the possibilities and limits of understanding the educational phenomenon), axiological issues (the values transmitted through the contents of education), normative issues (respecting certain ethical and judicial regulations) and dialectic issues (the temporal evolution of education).

Parts of these ideas are fathomed in the fourth and fifth chapters. Referring, for instance, to the "community, democracy, education" ternary, the author's reflection focuses on themes of real interest, such as: the learning situation and the common construction of knowledge, the dynamics of education and its explanation, the integrative role of schools for individuals and communities, cooperative learning and individual performances, civic education and civic activism in knowledge societies, the reformation of education and the intercultural context in education. The author also distinctively focuses on the idea of "school after school" as an educational alternative with a special importance due to its permanence, its closer proximity to the cultural artlessness of the group, its correspondence to the actual interests and needs of those being educated, its ability to correct disorganized situations in schools, its contribution to the shaping of the cultural identity of people and groups. For these reasons, says the author, 
"we must valorize complementary situations and formulas of education that the community generates, shares or supports at "a given time" (p.111).

In a continuation of these ideas, the authors then discusses numerous issues posed by the informatization of education and the dilemmas that this generates. After making a radiography of the new technological media in the educational context, professor Cucos pleads for an analysis of the introduction of alternative or digital manuals as a consequence of certain studies and pilot projects "in order to know the impact, the positive and negative reverberations, to correlate or correct these manuals with the realities and possibilities of the students, the schools and the teachers" ( $p$. 128-129).

Further on, he states that, as opposed to the classical manual, the digital manual "is a totally different product, built based on new principles of explaining the learning contents, after additional didacticization of the learning contents, and crafted on a learning philosophy which can enhance activism, interactivity, progress and creativity" (p.131). However, the author does not sympathize with the tendency of totally replacing the classical manual with its digital counterpart, supporting the development of an ideology of complementarity and the progressive annexation of the new learning resources. This is essential because, according to Constantin Cucos, there are learning situations and contexts when the interaction with the manual as an object is imposed for psychological, didactic and anthropological reasons.

The main thesis that the author promotes is that the relationship between information technology and education becomes more and more dynamic: on the one hand, we witness a permanent evolution of technical supports, which imposes the formation of new abilities, conducts and attitudes, and, on the other hand, the degree of assimilation of the new technologies in relation to the demands of education is more and more alert. The author even states that "the advance of technology is (also) a consequence of the force and amplitude of education, while education also specifically subsumes these benefits" (p.134). His conclusion is that information and communication technologies produce "multiple objectual, procedural, relational and valoric changes, which compels all of those who think and produce education to take these alterations in consideration, to assume them and to correlate them with the guidelines and finalities typical to formation" (p.136).

As I have mentioned before, the book is not only a principled approach of these problems of education, but also focuses on the changes that define the learning groups, the design of educational contents and pedagogical principles, the procedures which differentiate the values which are transmitted, the reformulation of the teaching - learning - evaluation strategy 
under the incidence of the new vectors or the rethinking of the relation of the school and knowledge up to a managerial, administrative and material level.

The process of training the teaching staff, an essential element of the quality of education, can also be included in the same context. From this perspective, the author presents practically applicable aspects, while the solutions that he proposes are meant to trigger "not only good intentions, but also profound reflection and the responsibility of those acting in the educational field. Here are some illustrations of the statements above: investing in human resources is a strategic factor of progress in the medium or long term; the need to impose the new training formulas in the already existing array of education; the tools of initial formation of teachers should be correlated to the perspective of continuous training; entering the training system must be conditioned by a test of aptitudes or knowledge; continuous evaluations should become sorting and crediting filters of teachers; the reevaluation of the strategies of practical training.

After having read the book, one can conclude that professor Cucos has a profound knowledge of the mechanisms which define the educational system in our country and of the way in which the political decision acts in this field. Starting from this aspect, he examines critically issues such as: the lack of consistency in the implementation of certain measures, the frequent alterations which occur in the educational system invoked by the so-called reform, the depreciation of the didactic function, poor valorization of field studies and expertise of the experts in the educational system, underfinancing education, the ambiguous law which encourages bureaucracy and the elements of voluntarism in adopting certain decisions.

One could undoubtedly mention further interesting aspects of the author's enterprise, but I will let the reader discover and analyze them from his/her own perspective. I would like to conclude by highlighting the colloquial style in which the text of the book is elaborated, the subtle way in which he correlates theoretical issues with practically applicable ones, as well as the numerous examples that he employs in order to facilitate the understanding of the wealth of ideas and opinions which we encounter as we read the book. All of these are, to my view, sufficient reasons to recommend this book not only to those training for a didactic career in the educational system, but also to the specialists or the people with the power to make decisions in this field. 